\title{
Kinin B1 receptor antagonism is equally efficient as angiotensin receptor 1 antagonism in reducing renal fibrosis in experimental obstructive nephropathy, but is not additive
}

\author{
Antoine Huart ${ }^{1,2}$, Julie Klein ${ }^{1,3}$, Julien Gonzalez ${ }^{1,3}$, Bénédicte Buffin-Meyer ${ }^{1,3}$, Eric Neau ${ }^{1,3}$, \\ Christine Delage $^{1,3}$, Denis Calise ${ }^{3,4}$, David Ribes ${ }^{1,2}$, Joost P. Schanstra ${ }^{1,3 *}$ and Jean-Loup Bascands ${ }^{1,3 *}$ \\ 1 Institut National de la Santé et de la Recherche Médicale U1048, Institute of Cardiovascular and Metabolic Disease, Toulouse, France \\ 2 Department of Nephrology, CHU-Rangueil, Toulouse, France \\ ${ }^{3}$ Université Toulouse III Paul-Sabatier, Toulouse, France \\ ${ }^{4}$ Unité mixte de Service USO06, CHU-Rangueil, Toulouse, France
}

\section{Edited by:}

Claudio M. Costa-Neto, University of Sao Paulo, Brazil

Reviewed by:

Md Abdul Hye Khan, Medical

College of Wisconsin, USA

Rita C. Tostes, University of Sao

Paulo, Brazil

*Correspondence:

Joost P. Schanstra and Jean-Loup Bascands, Institut National de la

Santé et de la Recherche Médicale U1048/I2MC-Equipe 12, Institute of

Cardiovascular and Metabolic

Disease, 1 avenue Jean Poulhès, BP

84225, 31432 Toulouse Cedex 4,

France

e-mail: joost-peter.schanstra@

inserm.fr;

jean-loup.bascands@inserm.fr
Background: Renal tubulointerstitial fibrosis is the pathological hallmark of chronic kidney disease (CKD). Currently, inhibitors of the renin-angiotensin system (RAS) remain the sole therapy in human displaying antifibrotic properties. Further antifibrotic molecules are needed. We have recently reported that the delayed blockade of the bradykinin B1 receptor $(B 1 R)$ reduced the development of fibrosis in two animal models of renal fibrosis. The usefulness of new drugs also resides in outperforming the gold standards and eventually being additive or complementary to existing therapies.

Methods: In this study we compared the efficacy of a B1R antagonist (B1Ra) with that of an angiotensin type 1 receptor antagonist (AT1a) in the unilateral ureteral obstruction (UUO) model of renal fibrosis and determined whether bi-therapy presented higher efficacy than any of the drugs alone.

Results: B1R antagonism was as efficient as the gold-standard AT1a treatment. However, bitherapy did not improve the antifibrotic effects at the protein level. We sought for the reason of the absence of this additive effect by studying the expression of a panel of genes involved in the fibrotic process. Interestingly, at the molecular level the different drugs targeted different players of fibrosis that, however, in this severe model did not result in improved reduction of fibrosis at the protein level.

Conclusions: As the B1R is induced specifically in the diseased organ and thus potentially displays low side effects it might be an interesting alternative in cases of poor tolerability to RAS inhibitors.

Keywords: angiotensin receptor inhibition, bradykinin B1 receptor, combined therapy, low density array, renal fibrosis

\section{INTRODUCTION}

The incidence and prevalence of chronic kidney disease (CKD) is increasing worldwide, largely due to the increasing incidence of type 2 diabetes and obesity (El Nahas, 2005; Vilayur and Harris, 2009; Levey and Coresh, 2012). Most patients with CKD progress toward end-stage renal disease (ESRD) within 10-30 years requiring renal replacement therapies. In addition to evolution toward ESRD, CKD is now recognized as a major risk factor for cardiovascular disease since patients with CKD are far more likely to die from cardiovascular pathologies than to develop ESRD (Keith et al., 2004). Delaying the progression of CKD will therefore not only reduce the number of patients ending up with ESRD, but also the number of patients with severe cardiovascular complications.

Renal tubulointerstitial fibrosis is the pathological hallmark of CKD. Although the initial renal disease leading to CKD can be different, the mechanisms leading to renal fibrosis are thought to be similar. Briefly, renal cell injury leads to the synthesis and secretion of cytokines and chemokines. In response to these inflammatory mediators, mononuclear cells progressively infiltrate the interstitial space and differentiate into macrophages. Macrophages perpetuate inflammation, leading to the proliferation of myofibroblasts, the cells responsible for the secretion of soluble pro-fibrotic molecules including growth factors, cytokines, chemokines, and extracellular matrix (ECM) proteins that contribute to progression of renal fibrosis. For in-depth reviews please refer to the following articles (Harris and Neilson, 2006; Duffield, 2014).

A multitude of events and factors were identified to be involved in the development of renal fibrosis, potentially leading to new antifibrotic strategies and compounds (Strutz, 2001; Iwano and 
Neilson, 2004; Vilayur and Harris, 2009). However, in humans, blockade of the renin-angiotensin system (RAS) remains the only effective therapy (Vilayur and Harris, 2009). Thus, any new potential anti-fibrotic therapy should be compared to angiotensin converting enzyme inhibition (ACEi) or AT1 receptor antagonists (AT1a). In addition, each new drug should be tested in combination with RAS inhibitors to determine the efficacy as an "add-on" drug.

We have reported (Klein et al., 2009) that the blockade of the bradykinin B1 receptor (B1R) was associated to a curative antifibrotic effect in the unilateral ureteral obstruction (UUO) model as well as in a model of glomerulonephritis (Klein et al., 2010).

The aim of the present study was to compare the antifibrotic potential of a B1R antagonist (B1Ra) to an AT1a in the UUO model and to investigate whether association of both compounds results in additive antifibrotic effects compared to each drug individually. Drugs were administrated at day 3 post-UUO to evaluate a curative effect.

We found that B1R antagonism was as efficient as the goldstandard AT1 antagonism. Bitherapy did not improve the antifibrotic effects histologically. However, we observed that, at the gene expression level, whereas each drug alone down-regulated significantly 29 and 17 genes (for ATla and B1Ra, respectively), bitherapy largely increased this number of down regulated genes.

\section{SUBJECTS AND METHODS DRUGS}

B1Ra SSR240612 was synthesized at Sanofi-Aventis R\&D Montpellier-France (Gougat et al., 2004). The SSR240612 solution was administered by gavage at a dose of $10 \mathrm{mg} / \mathrm{kg} / \mathrm{d}$ as described previously (Klein et al., 2010). AT1a (Valsartan was purchased from Novartis) was administrated by gavage at a dose of $30 \mathrm{mg} / \mathrm{kg} / \mathrm{d}$.

\section{ANIMALS}

We used C57Bl/6J mice (Harlan). The mice were housed in a pathogen-free environment. All experiments reported were conducted in accordance with the NIH guide for the care and use of laboratory animals and were approved by a local animal care and use committee (CEEA-122 2014-06).

Treatments with the AT1a and B1Ra were started 3 days after ureteral obstruction surgery and continued throughout the time (8 days) of obstruction. The control group received one hundred microliter of water by gavage. At the end of the different protocols, mice were sacrificed, and the kidneys were removed and divided in different parts according to the different protocols employed.

\section{UNILATERAL URETERAL OBSTRUCTION (UUO)}

Male mice of 8 weeks of age were used for these experiments. The unilateral ureteral ligation was performed as previously described (Schanstra et al., 2002; Klein et al., 2009). Briefly, under oxygenisoflurane anesthesia and through a longitudinal, left abdominal incision, the ureter was exposed and ligated with a $6 / 0$ nylon thread at the uretero-pelvic junction. In sham operations, the ureter was exposed but not ligated and repositioned. Mice were maintained on a standard mouse chow and tap water.

\section{IMMUNOHISTOCHEMISTRY AND HISTOLOGICAL ANALYSIS}

From paraffin-embedded kidney sections routine histology and immunohistological staining and analysis were performed as previously described (Schanstra et al., 2002; Pradere et al., 2007; Klein et al., 2009, 2010). Three- to four-micrometer sections were cut and used for routine staining (hematoxylin-eosin and Sirius red staining) and immunohistochemistry. For immunohistochemistry, mouse renal tissue were first de-waxed in toluene and rehydrated through a series of graded ethanol washes before endogenous peroxidase blockage. Specific primary antibodies were incubated ( $1 \mathrm{~h}$ at room temperature) on mouse kidney sections for the detection of collagen type III $(1 / 500)$ (Interchim), an extracellular matrix protein, or F4/80 (1/250) (RM2900; Caltag laboratories Inc., Burlingame, California, USA), as a marker of macrophages. For visualization we used the Dako Envision system. Sections were finally counterstained with hematoxylin. Negative controls for the immunohistochemical procedures included substitution of the primary antibody with non-immune sera.

Histomorphometric analyses were performed as recently described (Klein et al., 2009) using commercially available imageanalysis software that allows rebuilding of a kidney section from adjacent individual captures (Explora Nova Mosaïc software, La Rochelle, France). The number of colored pixel (red or brown) was determined, by blinded analysis. Results are expressed as percentage of specific colored pixel/total number of pixel analyzed.

\section{RNA EXTRACTION AND REVERSE TRANSCRIPTION}

Total RNA was purified from frozen renal tissues using the Qiagen RNeasy ${ }^{\circledR}$ Mini Kit following the manufacturer's protocol and digested with TURBO DNase ${ }^{\mathrm{TM}}$ (Ambion).

Total RNA was quantified by Nanodrop ND-1000 and the quality was checked using an Experion Automated Electrophoresis Station with a RNA StdSens Analysis Kit and Experion version 2.0 software (Bio-Rad). Ten micrograms of total RNA were transcribed into cDNA in a total volume of $100 \mu \mathrm{l}$ using the High Capacity cDNA Archive Kit and performed according the manufacturer's instructions (Applied Biosystems).

\section{TaqMan LOW DENSITY ARRAY (TLDA)}

The LDA contains eight samples-loading lines, each connected by microchannel to 48 miniature reaction chambers for a total of 384 wells per card. We created a « fibrosis》 taqMan Lowdensity array based on Applied biosystems 7900HT Microfluidic card. Gene-specific primers and FAM-labeled probes (Assayson-Demand, Applied Biosystems) were lyophilized in each well. We choose 96 genes (Supplementary Table 1): 92 fibrosis-related genes plus four housekeeping genes (Gapdh, Hmbs, Hprt, 18S) and configured our LDA cards with four identical 96 genes sets (two samples in duplicate). The four reference genes were chosen among 16 that we have tested for their relative stability expression. Indeed, it has been clearly shown that that normalization against a single reference gene is not any more acceptable (Murphy and Bustin, 2009). To reduce the risk of false interpretation of the gene expression variation, it is necessary to have a optimize normalization with several stable reference genes. To this end we have evaluated by qPCR the expression of 16 reference genes in 
our different experimental conditions. We used the free geNorm software to test the stability of 16 reference genes in normal and fibrotic conditions in presence or not of the different drugs. As shown in Supplementary Figure 1, the most stable genes in our different experimental conditions were Gapdh and Hmbs.

One Hundred nanograms of cDNA dissolved in 1X TaqMan Universal PCR MasterMix (Applied Biosystems) were added to each line of the array and the reaction was performed on $\mathrm{ABI}$ 7900 HT Fast Real-Time PCR System (Applied Biosystems). The PCR conditions were as follows: $2 \mathrm{~min}$ at $50^{\circ} \mathrm{C}, 10 \mathrm{~min}$ at $94.5^{\circ} \mathrm{C}, 40$ cycles of denaturation at $97^{\circ} \mathrm{C}$ for $30 \mathrm{~s}$, and annealing and extension at $59.7^{\circ} \mathrm{C}$ for $1 \mathrm{~min}$. The quantitative cycle $\mathrm{Cq}$ was automatically given by SDS 2.2 software package (Applied Biosystems). The relative amount of each gene mRNA to the mean of the two housekeeping genes (Gapdh and Hmbs) was calculated as $2^{-\Delta C q}$ where $\Delta C q=C q_{\text {gene }}-C q_{\text {mean of housekeeping genes. The }}$ fold-change of each gene mRNA to the normal condition was calculated as $2^{-\Delta \Delta C q}$ where $\Delta \Delta C q=\Delta C q_{\text {gene in fibrotic condition }}-$ $\Delta C q_{\text {gene in normal condition }}$.

\section{SEMIQUANTITATIVE RT-PCR}

Low density array data validation was performed for ten selected genes as described previously using the Gapdh as housekeeping gene (Bascands et al., 2009).

\section{STATISTICAL ANALYSIS}

Data are expressed as mean plus or minus SD. ANOVA with post-hoc Tuckey $\alpha$-test was performed for comparison between the different groups. $p$-values less than 0.05 were considered statistically significant.

\section{RESULTS}

\section{EFFECT OF DELAYED ADMINISTRATION OF AT1 AND B1R ANTAGONISTS ALONE OR IN COMBINATION ON RENAL TISSUE HISTOLOGY}

As expected, from the third day to the eight day after UUO we observed a progressive increase in macrophage infiltration and interstitial fibrosis (Figure 1). Both AT1a and B1Ra prevented significantly and at the same level the accumulation of macrophages and ECM. Co-administration of the two antagonists did not show an additional protective effect on the measured parameters.

\section{PROFILING OF GENES INVOLVED IN FIBROSIS}

To better understand the molecular mechanisms involved in the development of UUO-induced fibrosis and in the response to AT1 and $\mathrm{B} 1 \mathrm{R}$ antagonists we performed expression profiling of genes involved in the development of fibrosis. Figure 2 represents the expression variations of 87 genes out of the 93 studied since five genes (Ren2, Agtr2, Klklb1, Igf1, and Il6 which are highlighted in blue in Supplementary Table 1) were not detected in our conditions, due to either a very low expression level or a poor primer efficacy.

Among these 87 genes nine genes (Plau, Agtr1, Lnpep (IRAP), Tgfbr3, Smad7, Cdh2, Bad, Nfkbib, and Pax2) did not show significant variation after UUO, 13 genes were significantly downregulated and 65 genes were significantly up-regulated after 8 days UUO. Interestingly 17 out of the 65 up-regulated genes,
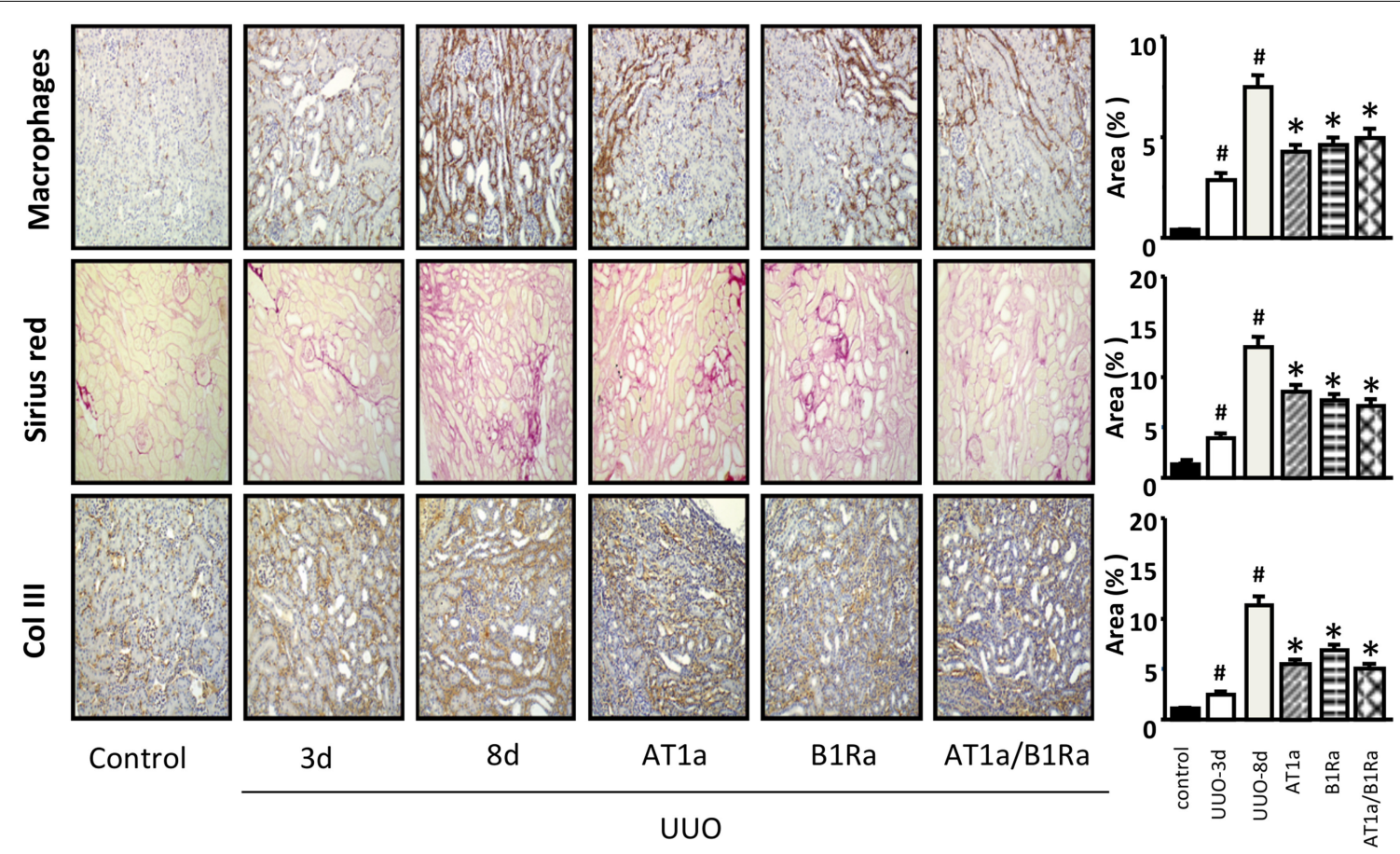

FIGURE 1 | Accumulation of macrophages, extracellular matrix (Sirius red) and collagen type III in obstructed kidneys 3 and 8 days after UUO and protective effect induced by administration of the AT1a, B1Ra or both starting at day $\mathbf{3}$ following ureteral obstruction surgery. Histograms represent the semi quantification of the immunohistological staining. $N=8$ /group. ${ }^{\#} P<0.05$ vs. control and ${ }^{*} P<0.05$ vs. UUO-8 days. 


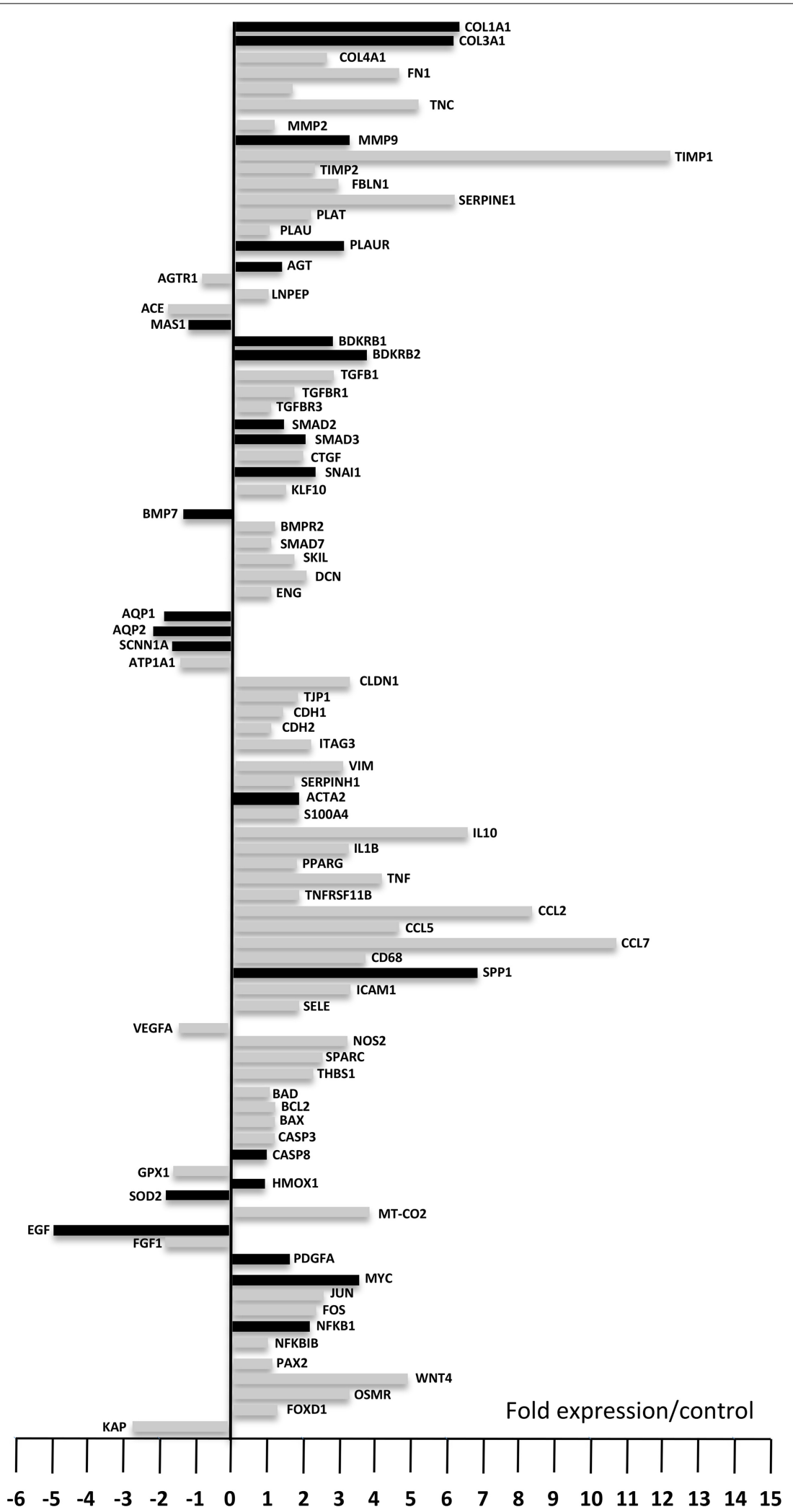

FIGURE 2 | Gene expression levels after 8 days of UUO compared to control. Down-regulated genes are displayed by the bars on the left while up-regulated genes are displayed on the right (fold expression compared to control). Black bars represent genes that already displayed up- or down-regulation 3 days after UUO. Each bar represents the mean from eight animals. Fold expression between -1 and +1 was considered not significant. 
Table 1 | RT-PCR validation of TaqMan Low Density Array (TLDA).

\begin{tabular}{lcc}
\hline Gene name & Fold expression-TLDA & Control RT-PCR \\
\hline Col3a1 & +6.27 & +3.97 \\
Timp1 & +12.34 & +22.75 \\
Plaur & +3.16 & +5.16 \\
Bdkrb1 & +2.97 & +3.24 \\
Tgfb1 & +2.95 & +6.13 \\
Bmp7 & -1.33 & -1.67 \\
Ccl7 & +10.89 & +36.21 \\
Nos2 & +3.22 & +7.07 \\
Mt-Co2 & +4.96 & +12.55 \\
Egf & -5.02 & -3.76 \\
\hline
\end{tabular}

RT-PCR values represent medium value of eight RT-PCR experiments.

and seven of the 13 down-regulated genes were already modified 3 days after UUO (Figure 2, black bars on the right and left-hand side, respectively). These variations were validated by semi-quantitative RT-PCR on 10 arbitrarily selected genes (Table 1).

\section{GENE EXPRESSION VARIATIONS INDUCED BY DELAYED ADMINISTRATION OF AT1 AND B1R ANTAGONISTS ALONE OR IN COMBINATION}

Table 2 shows $p$-values for genes expression differences in animals treated by AT1a or B1Ra or both antagonists after 8 days of UUO. In total, 29 genes were down-regulated by AT1a, 17 by $\mathrm{B} 1 \mathrm{Ra}$ and 54 by the combined treatment. Interestingly, 25 genes (highlighted in yellow) were not significantly down-regulated by the antagonists separately, however, the co-administration of both antagonists led to the significant down regulation of these genes. Moreover, whereas 15 genes (highlighted in green) and three genes (highlighted in orange) were specifically down-regulated by only one treatment (AT1a and B1Ra, respectively), combined treatment amplified down-regulation of 14 of these 18 genes as shown by the increased $p$-value (last column, Table 2 ). This effect was particularly marked for Ctgf (highlighted in blue). Conversely although the B1Ra significantly down regulated Snail, the addition of the AT1a led to a non-significant $p$-value. Similarly Wnt 4 and Nos2 were significantly down regulated by the ATla and became non-significant by the co-administration of the B1Ra.

\section{DISCUSSION}

The data presented in this study are the first evidence that delayed treatment with a B1R antagonist is as efficient as AT1 receptor antagonism to slow down renal tubulointerstitial fibrosis. The results also demonstrate that in our experimental conditions, the effects of both compounds are not additive. Indeed we do not observe a significant improvement of renal tubulointerstitial fibrosis, assessed by (immuno)histochemistry in the animal group treated with both antagonists compared to the renal protective effect observed with each agent individually. To understand the underlying mechanisms of these observations we have studied the expression level of a number of genes known to be involved in the renal fibrosis process.
Table 2 | Down regulated genes 8 days after UUO by either angiotensin type 1 receptor antagonist (AT1a), bradykinin type 1 receptor antagonist (B1Ra) or both AT1a/B1Ra treatments.

\begin{tabular}{|c|c|c|c|c|}
\hline & & AT1a & B1Ra & $\begin{array}{l}\text { AT1a/ } \\
\text { B1Ra }\end{array}$ \\
\hline \multicolumn{5}{|c|}{ MATRIX SYNTHESIS } \\
\hline Col1a1 & Collagen, type I, alpha 1 & 0.03 & NS & 0.004 \\
\hline Col3a1 & Collagen, type III, alpha 1 & 0.01 & 0.01 & 0.01 \\
\hline Col4a1 & Collagen, type IV, alpha 1 & 0.04 & NS & 0.02 \\
\hline Fn1 & Fibronectin 1 & 0.03 & NS & 0.005 \\
\hline Tnc & Tenascin C & 0.004 & NS & 0.007 \\
\hline \multicolumn{5}{|c|}{ MATRIX DEGRADATION } \\
\hline Mmp2 & $\begin{array}{l}\text { Matrix metallopeptidase } 2 \\
\text { (gelatinase A, } 72 \text { kDa gelatinase, } \\
72 \text { kDa type IV collagenase) }\end{array}$ & NS & NS & 0.003 \\
\hline Mmp9 & $\begin{array}{l}\text { Matrix metallopeptidase } 9 \\
\text { (gelatinase B, } 92 \text { kDa gelatinase, } \\
92 \text { kDa type IV collagenase) }\end{array}$ & 0.015 & NS & 0.02 \\
\hline Timp1 & TIMP metallopeptidase inhibitor 1 & NS & NS & 0.001 \\
\hline Timp2 & TIMP metallopeptidase inhibitor 2 & 0.015 & NS & 0.03 \\
\hline Fbln1 & Fibulin 1 & 0.015 & 0.045 & 0.004 \\
\hline $\begin{array}{l}\text { Serpine1 } \\
\text { (PAI1) }\end{array}$ & $\begin{array}{l}\text { Serpin peptidase inhibitor, clade E } \\
\text { (nexin, plasminogen activator } \\
\text { inhibitor type 1), member } 1\end{array}$ & 0.015 & NS & 0.001 \\
\hline Plat & Plasminogen activator, tissue & NS & NS & 0.01 \\
\hline Plaur & $\begin{array}{l}\text { Plasminogen activator, urokinase } \\
\text { receptor }\end{array}$ & NS & NS & 0.001 \\
\hline \multicolumn{5}{|c|}{ RENIN-ANGIOTENSIN SYSTEM } \\
\hline Mas1 & $\begin{array}{l}\text { MAS1 proto-oncogene, G } \\
\text { protein-coupled receptor }\end{array}$ & NS & NS & 0.03 \\
\hline \multicolumn{5}{|c|}{ BRADYKININ SYSTEM } \\
\hline Bdkrb2 & Bradykinin receptor B2 & 0.007 & 0.01 & 0.004 \\
\hline \multicolumn{5}{|c|}{ TGF $\beta$ 'S FAMILY } \\
\hline Tgfb1 & Transforming growth factor, beta 1 & NS & NS & 0.004 \\
\hline Tgfbr1 & $\begin{array}{l}\text { Transforming growth factor, beta } \\
\text { receptor } 1\end{array}$ & NS & NS & 0.015 \\
\hline Sma2 & SMAD family member 2 & NS & 0.04 & 0.024 \\
\hline Smad3 & SMAD family member 3 & NS & NS & 0.04 \\
\hline Ctgf & Connective tissue growth factor & NS & 0.01 & 0.00003 \\
\hline Snai1 & Snail family zinc finger 1 & NS & 0.009 & NS \\
\hline KIf10 & Kruppel-like factor 10 & NS & NS & 0.01 \\
\hline \multicolumn{5}{|c|}{ SIGNALING OF BMP7 } \\
\hline Smad7 & SMAD family member 7 & NS & NS & 0.046 \\
\hline Skil & SKI-like proto-oncogene & 0.04 & NS & 0.01 \\
\hline Den & Decorin & NS & NS & 0.02 \\
\hline Eng & Endoglin & NS & NS & 0.049 \\
\hline \multicolumn{5}{|c|}{ TUBULAR FUNCTION } \\
\hline Cldn1 & Claudin 1 & NS & NS & 0.03 \\
\hline Itga3 & $\begin{array}{l}\text { Integrin, alpha } 3 \text { (antigen CD49C, } \\
\text { alpha } 3 \text { subunit of VLA-3 receptor) }\end{array}$ & NS & NS & 0.01 \\
\hline \multicolumn{5}{|c|}{ MYOFIBROBLAST MARKERS } \\
\hline Serpinh1 & $\begin{array}{l}\text { Serpin peptidase inhibitor, clade } \mathrm{H} \\
\text { (heat shock protein } 47 \text { ), member } 1 \text {, } \\
\text { (collagen binding protein } 1 \text { ) }\end{array}$ & 0.0036 & 0.0085 & 0.0009 \\
\hline Acta2 & $\begin{array}{l}\text { Actin, alpha 2, smooth muscle, } \\
\text { aorta }\end{array}$ & NS & NS & 0.01 \\
\hline
\end{tabular}

(Continued) 


\section{AT1a B1Ra AT1a/} B1Ra

\begin{tabular}{|c|c|c|c|c|}
\hline \multicolumn{5}{|c|}{ TRANSCRIPTION FACTORS } \\
\hline Myc & $\begin{array}{l}\text { v-Myc avian myelocytomatosis viral } \\
\text { oncogene homolog }\end{array}$ & 0.0045 & 0.006 & 0.001 \\
\hline Jun & Jun proto-oncogene & 0.03 & 0.03 & 0.001 \\
\hline Fos & $\begin{array}{l}\text { FBJ murine osteosarcoma viral } \\
\text { oncogene homolog }\end{array}$ & 0.002 & 0.0045 & 0.0017 \\
\hline Nfkb1 & $\begin{array}{l}\text { Nuclear factor of kappa light } \\
\text { polypeptide gene enhancer in } \\
\text { B-cells } 1\end{array}$ & NS & NS & 0.036 \\
\hline \multicolumn{5}{|c|}{ DEVELOPMENT } \\
\hline Pax2 & paired box 2 & 0.04 & 0.02 & 0.0037 \\
\hline Wnt4 & $\begin{array}{l}\text { Wingless-type MMTV integration } \\
\text { site family, member } 4\end{array}$ & 0.0045 & NS & NS \\
\hline Osmr & Oncostatin M receptor & 0.015 & NS & 0.001 \\
\hline \multicolumn{5}{|c|}{ INFLAMMATION } \\
\hline$\| 1 \mathrm{~b}$ & Interleukin 1, beta & 0.003 & 0.009 & 0.001 \\
\hline 116 & Interleukin 6 & 0.01 & NS & 0.001 \\
\hline Pparg & $\begin{array}{l}\text { Peroxisome proliferator-activated } \\
\text { receptor gamma }\end{array}$ & NS & NS & 0.004 \\
\hline Tnf & Tumor necrosis factor & 0.005 & NS & 0.03 \\
\hline Tnfrsf11b & $\begin{array}{l}\text { Tumor necrosis factor receptor } \\
\text { superfamily, member } 11 \mathrm{~b}\end{array}$ & 0.03 & NS & 0.001 \\
\hline Ccl2 & Chemokine (C-C motif) ligand 2 & 0.002 & 0.002 & 0.001 \\
\hline Ccl5 & Chemokine (C-C motif) ligand 5 & 0.015 & 0.006 & 0.049 \\
\hline Ccl7 & Chemokine (C-C motif) ligand 7 & 0.002 & 0.002 & 0.001 \\
\hline Cd68 & CD68 molecule & 0.04 & 0.03 & 0.005 \\
\hline Spp1 & Secreted phosphoprotein 1 & NS & NS & 0.015 \\
\hline Icam1 & Intercellular adhesion molecule 1 & NS & NS & 0.015 \\
\hline Sele & Selectin E & NS & NS & 0.02 \\
\hline \multicolumn{5}{|c|}{ VASCULAR SYSTEM } \\
\hline Nos2 & Nitric oxide synthase 2 , inducible & 0.015 & NS & NS \\
\hline Thbs1 & Thrombospondin 1 & 0.0045 & 0.035 & 0.004 \\
\hline \multicolumn{5}{|c|}{ APOPTOSIS } \\
\hline Bad & $\begin{array}{l}\text { BCL2-associated agonist of cell } \\
\text { death }\end{array}$ & NS & NS & 0.049 \\
\hline Bax & BCL2-associated $X$ protein & NS & NS & 0.02 \\
\hline Casp3 & $\begin{array}{l}\text { Caspase } 3 \text {, apoptosis-related } \\
\text { cysteine peptidase }\end{array}$ & NS & NS & 0.02 \\
\hline Casp8 & $\begin{array}{l}\text { Caspase } 8, \text { apoptosis-related } \\
\text { cysteine peptidase }\end{array}$ & NS & NS & 0.02 \\
\hline \multicolumn{5}{|c|}{ OXYDATIVE STRESS } \\
\hline HMOX1 & Heme oxygenase (decycling) 1 & NS & NS & 0.03 \\
\hline Mt-Co2 & $\begin{array}{l}\text { Mitochondrially encoded } \\
\text { cytochrome c oxidase II }\end{array}$ & 0.007 & NS & 0.001 \\
\hline
\end{tabular}

Each value represents the p-value, NS, Non-Significant. Green boxes represent genes exclusively down regulated by AT1a. Orange boxes represent genes exclusively down regulated by the B1Ra. Yellow boxes represent genes exclusively down regulated by co-administration of AT1a and B1Ra. The additive effect of co-treatment for CTGF gene expression is highlighted in blue.

As already reported (Morrissey et al., 1996; Klahr, 2000; Chevalier et al., 2009; Duffield, 2014), we confirmed the up- or down-regulation of several genes involved in the renal fibrotic process following ureteral obstruction such as Tgfbl, Ctgf, collagens types (I, III, IV), fibronectin, Nfkb, growth factors, chemokines, etc... We also confirmed at the tissue level the antifibrotic effect of AT1a (Ishidoya et al., 1995) and B1Ra (Klein et al., 2009). At the gene level, 29 genes were modified by AT1a and 17 by B1Ra. Surprisingly, most of the genes down-regulated by the B1Ra were common to those modified by the ATla treatment, as only three out of 17 were specifically down-regulated by the B1Ra. However, it is very interesting to point out that the B1Ra specifically down-regulated Snail and Ctgf. Indeed, these two genes are crucial in the renal fibrotic mechanism since they are key downstream effectors of the TGF $\beta$ pathway and consequently significantly involved in the appearance of myofibroblasts and the production of ECM (Qi et al., 2005; Yoshino et al., 2007).

Interestingly, although each antagonist individually was able to induce down-regulation of fibrotic genes, a clear synergistic effect of the combination of both antagonists was observed on the expression of a number of genes. This point is illustrated by the significant further down-regulation of Tnfrsf $11 \mathrm{~b}$ in presence of both antagonists. This effect on Tnfrsf11b is quite relevant since the HSP47 is clearly involved in renal fibrogenesis through its role in collagen biosynthesis (Razzaque et al., 2005). In addition, in vivo, the use of small interfering RNA against Tnfrsf11b mRNA significantly decreases interstitial collagen accumulation (Xia et al., 2008).

Similarly, co-administration of both antagonists significantly down-regulated 25 genes that were not modified by the drugs alone including the profibrotic gene Tgfbl (Garcia-Sanchez et al., 2010) as well as nuclear factor Nfkb (Guijarro and Egido, 2001). The observed down-regulation of those two genes could in part explain the down-regulation of the other genes which are either under the direct control of NF- $\mathrm{KB}$ or stimulated by TGF $\beta 1$.

In addition we observed for around ten genes, mainly involved in extra-cellular matrix accumulation, an incremental nephroprotective effect by the addition of the B1Ra to the already well-known AT1a therapeutic effect. This effect was demonstrated by the increased $p$-values observed in the presence of both antagonists while for single administration, only the AT1a induced a significant down-regulation. Conversely whereas Smad2 and Ctgf were only down regulated by the B1Ra, the association of the ATla led to a significant decrease in the $p$-value. This drop in the $p$-value was particularly impressive for Ctgf. The down-regulation of Ctgf by the B1Ra was not unexpected since we have previously reported this effect (Klein et al., 2009) in the UUO model and an in-vitro study has demonstrated that the B1R stimulation induced collagen type I synthesis via stabilization of Ctgf mRNA (Ricupero et al., 2000). However, we did not expect exacerbation of the effect by the combination with an AT1a. This strongly suggests that both inhibitors stimulate different pathways leading to the inhibition of Ctgf expression. Indeed it is well-known that Angiotensin II induces TGF $\beta 1$ expression (Wolf, 2006) and the induction of CTGF by TGF $\beta 1$ has been shown to be Smad 3 and Smad4 dependent and Smad2 independent (Phanish et al., 2006). On the other hand we observed in the present study that the B1Ra induced an inhibition of Smad2 expression, which might represent an additional pathway in the regulation of Ctgf expression. On the contrary, as shown in Table 2, Snaill, Wnt4, and Nos2, which were significantly down-regulated either by the 
B1Ra or the AT1a became non-significantly down-regulated with the co-administration of both antagonists. Keeping in mind the role of Snaill and Wnt4 in the fibrotic process (Surendran et al., 2002), one could expect an impact on the loss of the epithelial phenotype leading to an increased appearance of myofibroblasts, however the significant decrease in the expression of Tnfrsf $11 \mathrm{~b}$ and Acta2, two myofibroblast-markers, do not comfort this hypothesis. Regarding Nos2 mRNA expression, a non-significant down-regulation might be beneficial since it suggests increased NO production, which is well-known to be nephroprotective (Morrissey et al., 1996).

Finally despite these positive effects observed at the level of gene expression we observed the absence of a visible protective effect at the tissue level at least in our experimental conditions. We hypothesize that the absence of effect at the tissue level has to be related to both the UUO model and the curative protocol used. The UUO model has the drawback of its advantages, it is an accelerated and reproducible in vivo model of renal fibrosis and therefore easy to use in the laboratory, but is far from mimicking the timescale of progression of fibrotic CKD which in human evolves over years. Thus, although the UUO model is widely used to identify early profibrotic events, potential profibrotic protein/pathways as well as antifibrotic molecules (Bascands and Schanstra, 2005), this model is most likely too drastic and not enough progressive to appreciate histologically any significant additive therapeutic effect. Indeed, although recent studies using this UUO model have reported additive antifibrotic effect of various drugs such as paricalcitol (Tan et al., 2009), pioglitazone (Higashi et al., 2010), and Rho-kinase inhibitor (Takeda et al., 2010) with renin angiotensin-inhibitors, those beneficial additive effects were obtained by preventive treatment, whereas in our study we attempted to demonstrate a therapeutic effect by administrating the compounds 3 days after induction of disease.

In summary the most important result of the present study is that kinin B1 receptor antagonism is as efficient in reducing renal fibrosis as angiotensin receptor 1 antagonism in the UUO model using a curative treatment protocol. This point has to be kept in mind because (i) the B1R is induced specifically in the diseased organ and thus potentially displays low side effects and (ii) it might become an alternative therapy in cases of poor tolerability due to the known adverse effects (chronic cough, hyperkalemia, angio-edema) of angiotensin converting enzyme inhibitors or to a lesser extent of AT1 receptor antagonist.

If targeting the renin-angiotensin system is now a welladmitted therapy for CKD, our data strongly suggested that a combination therapy associating an AT1a and a B1Ra might be much more effective to slow down the progression of renal fibrosis. However, this combination has to be evaluated in more chronic model (such as subtotal nephrectomy, glomerulonephritis, diabetic nephropathy) of renal disease associated to the slow progression of renal fibrosis.

\section{AUTHOR CONTRIBUTIONS}

Antoine Huart, Julie Klein, Julien Gonzalez, Eric Neau, Christine Delage and Denis Calise performed wet lab experiments. Bénédicte Buffin-Meyer, David Ribes, Joost P. Schanstra, and Jean-loup Bascands designed the study and wrote the manuscript.

\section{ACKNOWLEDGMENTS}

The work was funded by the Institut National de la Santé et de la Recherche Médicale (INSERM) and by an Agence National de la Recherche (ANR) Grant (ANR-12-BSV1-0035-01). SSR240612 was a kind gift of Sanofi-Aventis R\&D Montpellier-France (P. Carayon).

\section{SUPPLEMENTARY MATERIAL}

The Supplementary Material for this article can be found online at: http://www.frontiersin.org/journal/10.3389/fphar. 2015.00008/abstract

Supplementary Figure 1 | Average expression stability measure of the $\mathbf{1 6}$ reference genes. Transferrin C (Tfrc), Ubiquitin C (Ubc), phosphoglycerate kinase 1 (Pgk1), $\beta$ Actin (Actb), $\beta 2$ microglobulin (B2m), ribosomal protein L13A (Rpl13a), glucuronidase $\beta$ (Gusb), TATA box binding protein (Tbp), importin 8 (Ipo8), RNA polymerase II (RPII), peptidylprolyl isomerase A (Ppia), tyrosine 3-monooxygenase/tryptophan 5-monooxygenase activation zeta polypeptide (Ywhaz), ribosomal RNA 18S (18S), hypoxanthineguanine phosphoribosyltransferase (Hprt), glyceraldehyde-3-phosphate dehydrogenase (Gapdh), hydroxylmethylbilane synthase (Hmbs).

Supplementary Table 1 | Symbol, Name, and ID gene of the 96 genes present on the Low density Array.

\section{REFERENCES}

Bascands, J. L., Bachvarova, M., Neau, E., Schanstra, J. P., and Bachvarov, D. (2009) Molecular determinants of LPS-induced acute renal inflammation: implication of the kinin B1 receptor. Biochem. Biophys. Res. Commun. 386, 407-412. doi: 10.1016/j.bbrc.2009.06.063

Bascands, J. L., and Schanstra, J. P. (2005). Obstructive nephropathy: insights from genetically engineered animals. Kidney Int. 68, 925-937. doi: 10.1111/j.15231755.2005.00486.x

Chevalier, R. L., Forbes, M. S., and Thornhill, B. A. (2009). Ureteral obstruction as a model of renal interstitial fibrosis and obstructive nephropathy. Kidney Int. 75, 1145-1152. doi: 10.1038/ki.2009.86

Duffield, J. S. (2014). Cellular and molecular mechanisms in kidney fibrosis. J. Clin. Invest. 124, 2299-2306. doi: 10.1172/JCI72267

El Nahas, M. (2005). The global challenge of chronic kidney disease. Kidney Int. 68, 2918-2929. doi: 10.1111/j.1523-1755.2005.00774.x

Garcia-Sanchez, O., Lopez-Hernandez, F. J., and Lopez-Novoa, J. M. (2010). An integrative view on the role of TGF-beta in the progressive tubular deletion associated with chronic kidney disease. Kidney Int. 77, 950-955. doi: 10.1038/ki.2010.88

Gougat, J., Ferrari, B., Sarran, L., Planchenault, C., Poncelet, M., Maruani, J., et al. (2004). SSR240612 [(2R)-2-[((3R)-3-(1,3-benzodioxol-5-yl)-3-[[(6methoxy-2-naphthyl)sulfonyl]amino]propanoyl)amino]-3-(4-[[2R,6S)-2,6-

dimethylpiperidinyl]methyl]pheny $\quad$ l)-N-isopropyl-N-methylpropanamide hydrochloride], a new nonpeptide antagonist of the bradykinin B1 receptor: biochemical and pharmacological characterization. J. Pharmacol. Exp. Ther. 309, 661-669. doi: 10.1124/jpet.103.059527

Guijarro, C., and Egido, J. (2001). Transcription factor-kappa B (NF-kappa B) and renal disease. Kidney Int. 59, 415-424. doi: 10.1046/j.15231755.2001.059002415.x

Harris, R. C., and Neilson, E. G. (2006). Toward a unified theory of renal progression. Annu. Rev. Med. 57, 365-380. doi: 10.1146/annurev.med.57.121304. 131342

Higashi, K., Oda, T., Kushiyama, T., Hyodo, T., Yamada, M., Suzuki, S., et al. (2010). Additive antifibrotic effects of pioglitazone and candesartan on experimental renal fibrosis in mice. Nephrology 15, 327-335. doi: 10.1111/j.14401797.2009.01253.x

Ishidoya, S., Morrissey, J., McCracken, R., Reyes, A., and Klahr, S. (1995). Angiotensin II receptor antagonist ameliorates renal tubulointerstitial fibrosis caused by unilateral ureteral obstruction. Kidney Int. 47, 1285-1294. doi: 10.1038/ki.1995.183 
Iwano, M., and Neilson, E. G. (2004). Mechanisms of tubulointerstitial fibrosis. Curr. Opin. Nephrol. Hypertens. 13, 279-284. doi: 10.1097/00041552200405000-00003

Keith, D. S., Nichols, G. A., Gullion, C. M., Brown, J. B., and Smith, D. H. (2004). Longitudinal follow-up and outcomes among a population with chronic kidney disease in a large managed care organization. Arch. Intern. Med. 164, 659-663. doi: 10.1001/archinte.164.6.659

Klahr, S. (2000). Obstructive nephropathy. Intern. Med. 39, 355-361. doi: 10.2169/internalmedicine.39.355

Klein, J., Gonzalez, J., Decramer, S., Bandin, F., Neau, E., Salant, D. J., et al. (2010). Blockade of the kinin B1 receptor ameloriates glomerulonephritis. J. Am. Soc. Nephrol. 21, 1157-1164. doi: 10.1681/ASN.2009090887

Klein, J., Gonzalez, J., Duchene, J., Esposito, L., Pradere, J. P., Neau, E., et al. (2009). Delayed blockade of the kinin $\mathrm{B} 1$ receptor reduces renal inflammation and fibrosis in obstructive nephropathy. FASEB J. 23, 134-142. doi: 10.1096/fj.08115600

Levey, A. S., and Coresh, J. (2012). Chronic kidney disease. Lancet 379, 165-180. doi: 10.1016/S0140-6736(11)60178-5

Morrissey, J. J., Ishidoya, S., McCracken, R., and Klahr, S. (1996). Nitric oxide generation ameliorates the tubulointerstitial fibrosis of obstructive nephropathy. J. Am. Soc. Nephrol. 7, 2202-2212.

Murphy, J., and Bustin, S. A. (2009). Reliability of real-time reverse-transcription PCR in clinical diagnostics: gold standard or substandard? Expert Rev. Mol. Diagn. 9, 187-197. doi: 10.1586/14737159.9.2.187

Phanish, M. K., Wahab, N. A., Colville-Nash, P., Hendry, B. M., and Dockrell, M. E. (2006). The differential role of Smad2 and Smad3 in the regulation of pro-fibrotic TGFbetal responses in human proximal-tubule epithelial cells. Biochem. J. 393, 601-607. doi: 10.1042/BJ20051106

Pradere, J. P., Klein, J., Gres, S., Guigne, C., Neau, E., Valet, P., et al. (2007). LPA1 receptor activation promotes renal interstitial fibrosis. J. Am. Soc. Nephrol. 18, 3110-3118. doi: 10.1681/ASN.2007020196

Qi, W., Twigg, S., Chen, X., Polhill, T. S., Poronnik, P., Gilbert, R. E., et al. (2005). Integrated actions of transforming growth factor-betal and connective tissue growth factor in renal fibrosis. Am. J. Physiol. Renal Physiol. 288, F800-F809. doi: 10.1152/ajprenal.00179.2004

Razzaque, M. S., Le, V. T., and Taguchi, T. (2005). Heat shock protein 47 and renal fibrogenesis. Contrib. Nephrol. 148, 57-69. doi: 10.1159/000086043

Ricupero, D. A., Romero, J. R., Rishikof, D. C., and Goldstein, R. H. (2000). Des-Arg(10)-kallidin engagement of the B1 receptor stimulates type I collagen synthesis via stabilization of connective tissue growth factor mRNA. J. Biol. Chem. 275, 12475-12480. doi: 10.1074/jbc.275.17.12475

Schanstra, J. P., Neau, E., Drogoz, P., Arevalo Gomez, M. A., Lopez Novoa, J. M., Calise, D., et al. (2002). In vivo bradykinin B2 receptor activation reduces renal fibrosis. J. Clin. Invest. 110, 371-379. doi: 10.1172/JCI 0215493
Strutz, F. (2001). Potential methods to prevent interstitial fibrosis in renal disease. Expert Opin. Investig. Drugs 10, 1989-2001. doi: 10.1517/13543784.10.11.1989

Surendran, K., McCaul, S. P., and Simon, T. C. (2002). A role for Wnt-4 in renal fibrosis. Am. J. Physiol. Renal Physiol. 282, F431-F441. doi: 10.1152/ajprenal.0009.2001

Takeda, Y., Nishikimi, T., Akimoto, K., Matsuoka, H., and Ishimitsu, T. (2010). Beneficial effects of a combination of Rho-kinase inhibitor and ACE inhibitor on tubulointerstitial fibrosis induced by unilateral ureteral obstruction. Hypertens. Res. 33, 965-973. doi: 10.1038/hr.2010.112

Tan, X., He, W., and Liu, Y. (2009). Combination therapy with paricalcitol and trandolapril reduces renal fibrosis in obstructive nephropathy. Kidney Int. 76, 1248-1257. doi: 10.1038/ki.2009.346

Vilayur, E., and Harris, D. C. (2009). Emerging therapies for chronic kidney disease: what is their role? Nat. Rev. Nephrol. 5, 375-383. doi: 10.1038/nrneph.2009.76

Wolf, G. (2006). Renal injury due to renin-angiotensin-aldosterone system activation of the transforming growth factor-beta pathway. Kidney Int. 70, 1914-1919. doi: 10.1038/sj.ki.5001846

Xia, Z., Abe, K., Furusu, A., Miyazaki, M., Obata, Y., Tabata, Y., et al. (2008). Suppression of renal tubulointerstitial fibrosis by small interfering RNA targeting heat shock protein 47. Am. J. Nephrol. 28, 34-46. doi: 10.1159/000108759

Yoshino, J., Monkawa, T., Tsuji, M., Inukai, M., Itoh, H., and Hayashi, M. (2007) Snaill is involved in the renal epithelial-mesenchymal transition. Biochem. Biophys. Res. Commun. 362, 63-68. doi: 10.1016/j.bbrc.2007.07.146

Conflict of Interest Statement: SSR240612 was a kind gift of Sanofi-Aventis R\&D Montpellier-France. The authors declare that the research was conducted in the absence of any commercial or financial relationships that could be construed as a potential conflict of interest.

Received: 03 October 2014; accepted: 10 January 2015; published online: 02 February 2015.

Citation: Huart A, Klein J, Gonzalez J, Buffin-Meyer B, Neau E, Delage C, Calise $D$, Ribes D, Schanstra JP and Bascands J-L (2015) Kinin B1 receptor antagonism is equally efficient as angiotensin receptor 1 antagonism in reducing renal fibrosis in experimental obstructive nephropathy, but is not additive. Front. Pharmacol. 6:8. doi: 10.3389/fphar.2015.00008

This article was submitted to Experimental Pharmacology and Drug Discovery, a section of the journal Frontiers in Pharmacology.

Copyright (c) 2015 Huart, Klein, Gonzalez, Buffin-Meyer, Neau, Delage, Calise, Ribes, Schanstra and Bascands. This is an open-access article distributed under the terms of the Creative Commons Attribution License (CC BY). The use, distribution or reproduction in other forums is permitted, provided the original author(s) or licensor are credited and that the original publication in this journal is cited, in accordance with accepted academic practice. No use, distribution or reproduction is permitted which does not comply with these terms. 